\title{
Associations between sociocultural home environmental factors and vegetable consumption among Norwegian 3-5-year olds: BRA-study
}

Anne Lene Kristiansen ${ }^{1}$, Mona Bjelland ${ }^{1}$, Anne Himberg-Sundet ${ }^{1}$, Nanna Lien ${ }^{1}$ and Lene Frost Andersen $^{1}$

\section{Abstract}

The home environment is the first environment to shape childhood dietary habits and food preferences, hence greater understanding of home environmental factors associated with vegetable consumption among young children is needed.

The objective has been to examine questionnaire items developed to measure the sociocultural home environment of children focusing on vegetables and to assess the psychometric properties of the resulting factors. Further, to explore associations between the environmental factors and vegetable consumption among Norwegian 3-5 year olds.

Parents ( $n$ 633) were invited to participate and filled in a questionnaire assessing the child's vegetable intake and factors potentially influencing this, along with a 24-hour recall of their child's fruit and vegetable intake. Children's fruit and vegetable intakes at two meals in one day in the kindergarten were observed by researchers.

Principal components analysis was used to examine items assessing the sociocultural home environment. Encouragement items resulted in factors labelled "reactive encouragement", "child involvement" and "reward". Modelling items resulted in the factors labelled "active role model" and "practical role model". Items assessing negative parental attitudes resulted in the factor labelled "negative parental attitudes" and items assessing family pressure/demand resulted in the factor labelled "family demand". The psychometric properties of the factors were for most satisfactory. Linear regression of the associations between vegetable intake and the factors showed, as expected, generally positive associations with "child involvement", "practical role model" and "family demand", and negative associations with "negative parental attitudes" and "reward". Unexpectedly, "reactive encouragement" was negatively associated with vegetable consumption.

In conclusion, associations between sociocultural home environmental factors and children's vegetable consumption showed both expected and unexpected associations some of which differed by maternal education - pointing to a need for further comparable studies.

Keywords: Preschool children, home environment, sociocultural home environment, kindergarten, vegetables, Norway 
Research suggest that early nutrition are important for health later in life (Patro-Golab et al., 2016; Tandon et al., 2016; Zalewski et al., 2017). For example a recent systematic review on the association between diet in the preschool years and mental development show that overall, healthy dietary patterns in the preschool years are associated with better cognitive outcomes three to fifteen years later (Tandon et al., 2016). Inadequate consumption of fruits and vegetables is linked to an increased risk of non-communicable diseases such as cardiovascular diseases, cancers, chronic respiratory diseases and diabetes type 2 (Hu, Huang, Wang, Zhang, \& Qu, 2014; Li, Fan, Zhang, Hou, \& Tang, 2014; Wang et al., 2014). Evidence also indicates tracking of dietary intake from childhood to adulthood (Bjelland et al., 2013; Craigie, Lake, Kelly, Adamson, \& Mathers, 2011; Lien, Lytle, \& Klepp, 2001; Totland et al., 2013) hence early childhood represents a critical period for establishing long-lasting dietary habits (Bjelland et al., 2013). Despite health benefits of diets rich in fruits and vegetables, many countries face a challenge with regard to low intake of vegetables (Micha et al., 2015). This is also the case in Norway where the latest national dietary surveys among adults (Norwegian Directorate of Health, 2012), school children (Norwegian Institute of Public Health, 2016b) and preschool children (Kristiansen, Lande, \& Andersen, 2009; Norwegian Directorate of Health, 2002; Øverby, Kristiansen, Andersen, \& Lande, 2009) all report low consumption of vegetables.

In a life course perspective the home environment is acknowledged as the first environment to shape childhood dietary habits and food preferences (Rosenkranz \& Dzewaltowski, 2008). The home environment can be characterized by three domains; the physical environment, the sociocultural environment and the political/economic environment (Rosenkranz \& Dzewaltowski, 2008), where each environment individually could play an important role through a variety of factors influencing vegetable consumption among young children. Reviews primarily including school aged-children show that home availability and accessibility are strong positive physical factors associated with fruit and vegetable consumption (Blanchette \& Brug, 2005; Cook, O'Reilly, DeRosa, Rohrbach, \& SpruijtMetz, 2015; Krolner et al., 2011; Pearson, Biddle, \& Gorely, 2009; Rasmussen et al., 2006; van der Horst et al., 2007). This is also supported by findings from our study among Norwegian 3-5 year olds, where home availability and accessibility are positively associated with vegetable consumption (Kristiansen, Bjelland, Himberg-Sundet, Lien, \& Andersen, 2017). One area within the sociocultural home environment of young children that has received a lot of attention lately is parental feeding practices. A range of instruments to measure parental feeding practices has been developed (de Lauzon-Guillain et al., 2012; O'Connor et al., 2016; Vaughn, Tabak, Bryant, \& Ward, 2013). Inconsistency in labelling and definitions used for describing such practices make comparisons across studies challenging (Gevers, Kremers, de Vries, \& van Assema, 2014; Vaughn et al., 2013; Vaughn et al., 2016). Still, reviews among children up to 18 years of age point to parental intake, parental modelling and parental encouragement as important sociocultural factors positively associated with 
2006; van der Horst et al., 2007). Finally, as an economic home environmental factor, high parental socioeconomic position is associated with higher fruit and vegetable intake among children (Krolner et al., 2011; Rasmussen et al., 2006; van der Horst et al., 2007). It is important to note that associations between characteristics of the home environment and vegetable intake often are reported together with fruit intake (Blanchette \& Brug, 2005; Krolner et al., 2011; Rasmussen et al., 2006; van der Horst et al., 2007) even though there are likely to be differences in factors associated with the two food groups (Glasson, Chapman, \& James, 2011), hence greater understanding of home environmental factors associated with vegetable consumption among young children is needed.

Although there are a large number of instruments developed to assess parental feeding practices in general, the advantage of more specific measurements of the sociocultural home environment focusing on vegetables (e.g. parental vegetable feeding practices) is so far less explored (Vaughn et al., 2016). The present study aims to address this gap by firstly examining item pools developed to measure the sociocultural home environment of Norwegian preschool children focusing on vegetables, and to assess the psychometric properties of the resulting factors. Moreover, the study aims to explore associations between factors of the sociocultural home environment and vegetable consumption among these children.

\section{Methods}

\section{Study design and subjects}

The BRA-study (an acronym for the Norwegian words "Barnehage" (kindergarten), "gRønnsaker" (vegetables) and "fAmilie" (family)) is an intervention study with an overall aim to improve vegetable intake among preschool children (3-5 years at baseline) through changing the food environment and dietary practices in the kindergarten and the home. More specifically, the aim was to increase the daily frequency of vegetable intake, was to increase the variety of vegetables eaten over a month and was to increase the daily amount of vegetables consumed. The target group for the BRA-study is preschool children born in 2010 and 2011, attending public or private kindergartens in the counties of Vestfold and Buskerud, Norway. All 479 public and private kindergartens in these two counties were invited by letter to participate in the BRA-study. Seventy-three kindergartens chose to participate (response rate $15.2 \%$ ). Parents of 1631 children born in 2010-2011 in the 73 kindergartens were invited by letter to participate. Parental consent was obtained for 633 children (response rate 38.8\%). Families were allowed to participate with more than one child ( $n 45$ children in total sample were siblings). Number of participating children in each kindergarten varied from no children up to 23 children. For the present study, only data from the baseline surveys among parents and the baseline observation (see Step 1-3 below) of the children were included.

This study was conducted according to the guidelines laid down in the Declaration of Helsinki and all procedures involving human subjects/patients were approved by the Norwegian Social Science Data 
Services. Written informed consent for the child was obtained from all parents who agreed to participate ( $n$ 633).

\section{Design and methods}

The design of the study is similar to that presented earlier (Kristiansen et al., 2017). In brief, data about the child and the home environment were collected in three steps at baseline (Figure 1): Step 1) a parental web-based questionnaire assessing frequency and variety of the child's vegetable intake, as well as factors potentially influencing the child's vegetable consumption was filled in for 439 children (69\% of the 633 participants).

Step 2 ) among a subsample ( $n$ 411) of the participating children (65 \% of the 633 participants), a direct observation of the children's fruit, berries and vegetable intakes at two meals in one day in the kindergarten was conducted.

Step 3) a parental web-based 24-hour recall for assessing the child's intake of fruit, berries and vegetables was filled in for 470 children (74\% of the 633 ).

Number of children having data from all three steps was 246.

\section{Step 1: A parental web-based questionnaire}

In March 2015, all parents of participating children in the BRA-study ( $n$ 633) received a link to a webbased questionnaire by e-mail. If the family participated with more than one child, parents were instructed to answer separately for each child. One e-mail reminder was sent out to non-responders about 3 weeks after the first e-mail.

The questionnaire had been tested in a pilot study with 10 mothers and then revised, for more information see Kristiansen et al. (Kristiansen et al., 2017). The final questionnaire included 53 questions, divided in two parts. The first part of the questionnaire primarily aimed to measure the usual vegetable intake, and parents were asked to think about the last couple of months. Frequency and variety of 18 different types of vegetables were assessed with the question "How often does your child eat the following vegetables?". Response alternatives were "never" (0 times per day), "1-3 times a month" (0.07 times per day), "1 time per week" (0.14 times per day), "2 times per week" (0.29 times per day), "3 times per week” ( 0.43 times per day), “4 times per week” ( 0.57 times per day), "5 times per week" (0.71 times per day), "6 times per week" (0.86 times per day), “every day" (1.0 time per day) and " 2 or more times per day" (2.0 times per day). This question was modified from the national dietary survey among Norwegian 2-year olds (Kristiansen et al., 2009) mapping total dietary intake. A validation study has been undertaken for that survey, but not for the modified question used in this study. Potatoes, pickled and preserved vegetables (due to salt and sugar content) were not included as vegetables in the present study.

The second part of the questionnaire aimed to measure potential factors within the home environment assumed to be related to vegetable intake. Item pools related to the physical home environment have 
been published elsewhere (Kristiansen et al., 2017). In the present paper, only item pools related to the sociocultural home environment, i.e.: parental encouragement (15 items), parental modelling (6 items), negative parental attitudes ( 4 items) and family pressure/demand (4 items) will be presented. The items were modified versions of statements and questions used in previous Norwegian and international studies among children aged 2-12 years (Baranowski et al., 2013; Bjelland et al., 2011; Haszard, Williams, Dawson, Skidmore, \& Taylor, 2013; Musher-Eizenman \& Holub, 2007; O'Connor et al., 2010; Zeinstra, Koelen, Kok, van der Laan, \& de Graaf, 2010). A translation and backtranslation of statements and questions available in English were conducted by fluent speakers of the English and Norwegian languages. Responses were given on a 5-point Likert response scale ranging from "totally disagree" $(=1)$ to "totally agree" $(=5)$, with a neutral midpoint ("neither"=3). Factor values were calculated as the mean score of the items comprising the factor.

The questionnaire also collected data on child gender, child birth year, number of siblings in the household, age of the respondent, respondent's relation to the child, cohabitant status of the respondent, nationality of the respondent and nationality of the mother/father of the child. Maternal and paternal educational level was assessed in the consent form. The educational level was assessed by four precoded categories, which were combined into two categories in the analysis: low education (upper secondary school or less) and high education (university college/university). Maternal education was used as an indicator of the socioeconomic position of the family as maternal education was reported with lower missing compared to paternal education.

\section{Step 2: Direct observation}

As part of the baseline data collection, the research team members visited all the 73 kindergartens in April to June 2015. Direct observation was conducted if the kindergarten had three or more participating children in a department. Each researcher observed one to four children simultaneously, with a maximum of eight children from each kindergarten being observed. Preferably, children of mothers with a low educational level were observed and otherwise children were chosen for observation at random. During observations, the researchers were standing close to tables where the children sat, and recorded intake of fruit, berries and vegetables on an observational form. These foods could be provided by the kindergarten, by the parents or by both the kindergarten and the parents. As children in kindergartens often are offered sliced fruit and vegetables rather than whole pieces, a coloured picture sheet accompanied the observational form to assist researchers in deciding the portion size. The picture sheet contained pictures of nine different shapes i.e. slice of cucumber, stick of sweet pepper, section of orange, piece of a banana etc. In general, most kindergartens in Norway serve a hot meal for lunch once a week (Norwegian Directorate of Heath, 2012). Therefore, two photograph series with four different portion sizes of a vegetable soup and a vegetable stew were included, for more information see Kristiansen et al.(Kristiansen et al., 2017). 
The researchers gave all participating children ( $n$ 633) a card to take home, which informed about types of fruits, berries and vegetables served in the child's kindergarten department on that particular day. Moreover, the card informed parents that they would receive an e-mail from the research team about the 24-hour recall (see step 3).

All researchers were trained in observation and all procedures and measurements were conducted according to a standardized protocol.

During data collection there were occasionally options for two researchers to observe the same child/children to assess interrater reliability (IOR) between the pair of observers. IOR was assessed in 16 kindergartens, with the first pair of observers carrying out duplicate observations of 66 children simultaneously, while the second pair of observers carrying out 12 duplicate observations. The level of agreement between pairs of observers was estimated by calculating the intraclass correlation (ICC). The ICC for the first pair of observers was 0.96, while for the second pair it was 0.97 .

\section{Step 3: A parental web-based 24-hour recall}

In the evening (after nine pm) on the day of the direct observation (step 2), all parents received a link to a web-based 24-hour recall by e-mail and they were asked to complete the questionnaire within the next 24 hours. If the family participated with more than one child, parents were instructed to answer separately for each child. One e-mail reminder was sent out to non-responders two days after the first e-mail. In this reminder, parents were asked to recall the child's intake for the day of the observation. The 24-hour recall was designed to measure the participating child's intake of fruit, berries and vegetables, with an extra focus on vegetable intake. To ease the reporting, the 24- hours were divided into six eating occasions: breakfast, snack meal 1 (intake after breakfast, but before lunch), lunch, snack meal 2 (intake after lunch but before dinner), dinner and snack meal 3 (intake after dinner and until the child went to bed).

For breakfast, snack meal 1 and snack meal 3, frequencies and amount of six different types of vegetables were reported. For lunch, snack meal 2 and dinner frequencies and amount of 12 different types of vegetables were reported. The last question in every eating occasion was open-ended. However, due to the variable quality of this data and the workload required for coding this data, information from such questions were not included. Decisions for the vegetable list was based on the Norwegian meal pattern and the most sold vegetables. To assist parents in reporting amount of vegetables eaten, photo series with four different portion sizes was used. However, photos of the amount of vegetables were only displayed if that particular vegetable was reported. The focus was on weekday intake of vegetables, therefore 24-hour recalls reporting on vegetable intake during a weekend day were not included.

Parents who completed both web-based questionnaires (step 1 and step 3) were entered in a lottery with rewards; two of about 535 Euros and one of about 1070 Euros. 
220 The web-based questionnaire (step 1) provided information about frequency and variety of vegetable

221

222

223

224

225

226

227

228

229

230

231

232

233

234

235

236

237

238

239

240

241

242

243

244

245

246

247

248

249

250

251

252

253

254 intake. The frequency of the 18 vegetables was added up to give the daily frequency (mean 3.1, SD 1.8). For variety, the ten categories of vegetable frequency were combined into two groups. Those who reported intake of a particular vegetable to be "1-3 times a month" or more often was regarded as "users", while those who reported intake to be "never" was regarded as "non-users" (less than $2 \%$ in total). Total variety per month was calculated by adding up users of the 18 vegetables (mean 10.4, SD 4.3).

Parental ability to recall their child's diet when the child is in child-care may be a limiting factor when using dietary recall methodology among preschool children (Andersen et al., 2011; Baranowski, Sprague, Baranowski, \& Harrison, 1991). Therefore, amount of vegetables consumed in one day was calculated based on data from the direct observation when in kindergarten (step 2) and the 24-hour recall when at home (step 3). Hence, only children with data from both step 2 and step 3 were eligible to be included in analyses considering amount of vegetables. In the 24-hour recall, the parental reported intake of vegetables at lunch and at snack meal 2 was replaced by the observed vegetable intake in the kindergarten. However, if a child had been picked up from the kindergarten before snack meal $2(n=15)$, only the lunch meal was replaced in the 24-hour recall.

\section{Data analysis}

Participants included in data analysis varied for the different methods used. For the PCA, participants included were those with data from the parental web-based questionnaire (Step 1, $n$ 439). This sample was also eligible to be included in the linear regression analysis, however due to missing data for covariates (primarily maternal education) the number of participants in the linear regression analyses for variety and frequency was 395 . For the analysis regarding amount of vegetables consumed, participants also had to have data from both step 2 and step 3. There were 246 participants with such data, however 27 were lost due to missing data on covariates (primarily maternal education) and 22 were lost due to reporting vegetable intake of a weekend day in the $24 \mathrm{~h}$ recall, leaving 197 participants to be included in the analysis concerning amount of vegetables consumed.

PCA was used for exploring the item pools for factors assumed to be related to vegetable intake. All items asked about in an item pool were entered into PCA. The number of factors retained from the PCA was chosen on the basis of the eigenvalue (explained variance), with the decision criterion of $\geq$ 1.0, and the interpretability of the factors. For parental encouragement the first three factors were chosen for further analysis. The remaining factors all had eigenvalue less than 1.0, and thus individually explained only a small fraction of the overall variance in the data. To improve the interpretation of the data, the three-factor solution was rotated by varimax rotation. For parental modelling a two-factor solution was chosen for further analysis, while for the item pools assessing 
negative parental attitudes and family pressure/demand one factor for each pool was chosen for further analysis.

Items were considered to load on a factor if they had factor loadings $>0.3$ (Kline P, 1994). Items not loading on a factor (factor loading $<0.3$ ) were eliminated. Items with high loading on more than one factor were included in the factor where they had the highest loading.

To assess the psychometric properties (a measure of reliability and validity) of the new factors derived from the PCA, Cronbach's alpha and corrected item-total correlation (CITC) was calculated as a measure of internal reliability. A CITC $>0.30$ were considered good and $<0.15$ were considered unreliable since that would indicate lack of homogeneity of the items within an item pool (Nunnally JC, 1994). Cronbach's alpha values of 0.70 or above are normally acceptable values, however values of 0.6-0.7 are often considered acceptable in exploratory analyses, especially if the factor includes only a few items (Field, 2009; Tavakol \& Dennick, 2011). Further, validity of the new factors derived from the PCA was assessed by construct validity by means of assessing associations between the new factors of the sociocultural home environment and vegetable consumption.

Clustering effects due to kindergartens being the unit of recruitment were checked using the Linear Mixed model procedure (Heck, Thomas, \& Tabata, 2010). The unexplained variance in frequency, variety and amount of vegetables at the kindergarten level was 0 to $1.6 \%$, which is considered so low that clustering effect was not taken into account in the analysis.

Linear regression was applied to assess the relationship between variety, frequency and daily amount of vegetable intake among the 3-5 year olds and the seven factors derived from the PCA ("reactive encouragement", “child involvement", "reward", "active role model”, "practical role model”, "negative parental attitudes" and "family demand"). For every child a composite score for each of the seven new factors was created, and this score was further used in linear regression analysis. To be included in the linear regression analysis according to "reactive encouragement", subjects had to have responses on 4 out of 5 items, for "child involvement" subjects had to have response on 6 out of 7 items while for "reward" subjects had to have response on 2 out of 3 items. To be included in the linear regression according to "active role model" subjects had to have responses on 2 out of 3 items and likewise for the factor "practical role model". To be included in the linear regression according to "negative parental attitudes" subjects had to have responses on 3 out of 4 items and similarly for the factor "family demand".

All models were adjusted for child gender, child birth year and maternal educational level. Interactions between maternal education and each of the seven factors were tested for the factors which had significant associations in the linear regression analysis. All $P$ values are two-sided, and $P$ values less than 0.05 were considered statistically significant. All statistical analyses were performed by IBM® SPSS® Statistics, version 22.0 (IBM Corporation).

\section{Results}


Table 1 presents selected characteristics of the children and their parents analysed in PCA. Boys and girls were equally represented as was child year of birth. Parental respondent age was between 24 and 60 years, with a mean age of 35.4 years $(\mathrm{SD}=5.1)$. Most of the respondents were mother of the child, and most parents were Norwegians or from other European countries and had higher education. The samples used in the regression analysis ( 395 and $n$ 197) had roughly the same distribution in characteristics as those presented in Table 1. For example, the proportion of mothers with low education in the sample of $n 395$ was equal to that of $n 439$ (29\%), while it was $32 \%$ in the sample of $n$ 197. Descriptive statistics for vegetable intake are also presented in Table 1.

According to the reported variety and frequency of vegetable intake, less than $2 \%$ of the children reported consumption to be "never". According to the observation and the 24-hour recall data, results showed that less than $6 \%$ of the children did not consume vegetables at all on the day when observations and recalls were done (data not shown).

\section{Exploration of item pools developed to measure the sociocultural home environment}

For the 15 parental encouragement items, the three factors derived from PCA were labelled "reactive encouragement" (5 items), "child involvement" ( 7 items) and "reward" (3 items) (Table 2). These three factors explained approximately $47 \%$ of the total variance. For the six parental modelling items, the two factors derived from PCA were labelled "active role model" ( 3 items) and "practical role model" ( 3 items), explaining $62 \%$ of the total variance. For the four parental attitude items, the one factor derived from PCA was labelled "negative parental attitudes" (4 items). This factor explained $44 \%$ of the total variance. For the four family pressure/demand items, the one factor derived from PCA was labelled "family demand" (4 items), explaining approximately 57\% of the variance. Most items within each of the seven new factors had high factor loadings (i.e. $\geq 0.6$ ) and all items from the questionnaire were included in the final factor structures.

Table 3 presents the mean values and the psychometric properties of the seven factors derived from the PCA. The mean score for "reactive encouragement", "practical role model" and "active role model" was high, 4.47, 4.37 and 3.90 respectively, indicating that most parents partly agreed with the statements included in those factors. The mean score for "child involvement" were slightly above the neutral midpoint of three. Finally, the mean score for "negative parental attitudes", "family demand" and "reward" was below three, indicating that most parents partly disagreed with the statements included in those factors. Most values for the CITC were 0.30 or above, and Cronbach's alpha values ranged from 0.57 to 0.74 .

\section{Associations between factors of the sociocultural home environment and vegetable consumption} Two out of three factors measuring parental encouragement showed negative associations with vegetable consumption (Table 4). Every unit increase in the factor "reactive encouragement" was associated with a reduction in vegetable variety of about 0.7 types per month $(P=0.046)$ and a 
reduction in mean amount of vegetables consumed of 26 grams a day $(P=0.009)$. The factor "reward" was negatively associated with variety and frequency of vegetable intake, where every unit increase in the factor was associated with a reduction in vegetable variety of about 0.6 types per month $(P=$ $0.008)$ and a reduction in vegetable frequency of more than 0.3 times per day $(P<0.001)$. For the factor "child involvement" there was a significant interaction with maternal education and variety in vegetable intake $(P=0.022)$ and frequency of vegetable intake $(P=0.003)$. Among children of highly educated mothers every unit increase in this factor was associated with an increase in vegetable variety of nearly 1 type per month $(P=0.004)$ and an increase in frequency of vegetable intake of more than 0.5 times per day $(P<0.001)$. No significant associations were seen among children of low educated mothers.

For the two factors measuring parental modelling, only the factor "practical role model" was significantly associated with vegetable consumption. Every unit increase in this factor was associated with an increase in variety of vegetable intake of more than 1 type per month and an increase in frequency of vegetable intake of about 0.6 times per day (both $P$-values $<0.001$ ). The factor "negative parental attitudes" was negatively associated with vegetable intake. Every unit increase in this factor was associated with a reduction in variety of vegetables of approximately 0.9 types of vegetables per month $(P=0.026)$ and a mean reduction of about 30 grams vegetables a day $(P$ $=0.009$ ).

For the factor "family demand" there was a significant interaction with maternal education and variety in vegetable intake $(P=0.009)$. Among children of highly educated mothers every unit increase in this factor was associated with an increase in vegetable variety of about 1 type per month $(P=0.001)$ while no significant association was seen among children of low educated mothers.

\section{Discussion}

Presented in this paper are seven distinct factors of the sociocultural home environment of Norwegian 3-5 year olds with regards to vegetable consumption. The psychometric properties of the factors were for most satisfactory. Factors and children's vegetable consumption showed both expected and unexpected associations some of which differed by maternal education.

\section{Psychometric properties of factors}

Most of the items used in the present study were composed of modified versions of statements and questions used in previous Norwegian and international studies among preschool and school-aged children (Baranowski et al., 2013; Bjelland et al., 2011; Haszard et al., 2013; Musher-Eizenman \& Holub, 2007; O'Connor et al., 2010; Zeinstra et al., 2010), resulting in unknown reliability and validity of those in the initial item pools.

The psychometric properties of the factors in the present study were for most satisfactory, probably indicating suitability for use among parents of children in general. Yet, more studies are needed to 
verify this. According to reliability of the new factors, most items correlated with the factor to a good degree by having values above 0.3 , additionally, no items had correlations below 0.15 (Nunnally JC, 1994). Cronbach's alpha values ranged from 0.57 to 0.74 indicating generally acceptable internal consistency of the new factors. Those factors with the lowest Cronbach's alpha included only 3 or 4 items, and they also included items with the lowest values of CITC. Cronbach's alpha is sensitive to the number of items included in a scale, with increasing numbers of items in a scale possibly resulting in an increased value (Field, 2009). None of the factors in the present study included more than seven items, so this has probably not affected the results. Appropriate sample size when conducting PCA has been debated, but it seems reasonable to include a minimum of 300 participants (Field, 2009). PCA was conducted on a sample consisting of more than 400 participants; hence the criterion of an adequate sample size was fulfilled.

\section{Associations between factors of the sociocultural home environment and vegetable consumption}

\section{Encouragement}

Studies among school-aged children often indicate positive associations between parental encouragement and children's vegetable intake (Pearson et al., 2009), and this has also been reported in studies including preschool children (McGowan, Croker, Wardle, \& Cooke, 2012; Vereecken, Keukelier, \& Maes, 2004). In the present study, two out of three factors measuring parental encouragement were negatively associated with vegetable consumption. This might suggest that instruments developed to assess parental feeding practices in general and instruments focusing on parental vegetable feeding practices in particular, might provide different results. Further, as number of items included in an instrument varies, this also might explain the differences in the results obtained.

The factor "reactive encouragement" was negatively associated with vegetable consumption, yet items included in the factor were items reflecting helpful encouragement for vegetable consumption like "I encourage my child to try a few bites of the vegetables". The mean score for this factor was high (4.47), indicating that most parents partly agreed with the items included in this factor. A similar finding was reported in a study among 4-12 year olds from the Netherlands (Zeinstra et al., 2010), where "positive information" was negatively associated with children's vegetable intake. Items included in this factor were "Do you tell your child vegetables are healthy?", "Do you tell your child vegetables are tasty?", "Do you tell your child vegetables are good for them?" and "When you eat vegetables, do you show your child that you like them?". It might be that parents use strategies like "reactive encouragement" and "positive information" because their child is unwilling to consume vegetables, but it might also be that verbally promoting vegetable intake can increase vegetable intake to a certain point, but that tendencies to nagging have an opposite effect.

The factor "reward", including one item assessing food-based bribes to eat vegetables, was also negatively associated with vegetable intake among the 3-5 year olds in the present study. Food-based 
bribes to eat have been shown to increase the liking for the bribe food, but decrease liking and intake of healthy foods such as vegetables (Blissett, 2011; Vaughn et al., 2016).

Lastly, "child involvement" was positively related to frequency and variety of vegetable intake among children of highly educated mothers, while among children of low educated mothers, no significant associations were seen. Increased autonomy for the child towards vegetable intake (e.g. "I ask my child to help select vegetables at the grocery store") is likely to be favourable; however why this association was not observed for children of low educated mothers needs further elaboration. Currently there is limited research regarding child involvement in cooking, food or meal preparation (DeCosta, Moller, Frost, \& Olsen, 2017; Vaughn et al., 2016).

\section{Modelling}

Of the six items used to assess parental modelling in the present study, four items were taken from the "modelling" factor in the Comprehensive Feeding Practices Questionnaire (CFPQ) (Musher-Eizenman \& Holub, 2007). Items from the CFPQ were modified by replacing the word "healthy" with the word "vegetables" (e.g. "I try to show enthusiasm about eating vegetables"). The validation study of the CFPQ among American 2-8 year olds showed that parents who reported "feeling more responsible for their children's eating habits" also reported more modelling (Musher-Eizenman \& Holub, 2007).

Three out of the four CFPQ-items loaded onto the factor "active role model", but no significant associations with vegetable intake was seen for this factor.

The second factor of parental modelling in the present study included items reflecting a more practical form of modelling (e.g. "I let my child assist in preparing vegetables (peeling, cutting, put on plates etc.)"). This factor was significantly and positively associated with variety and frequency of vegetable intake. It seems likely that when including children in for example preparing vegetables they will be more interested in eating vegetables. In the review by Pearson and co-workers, including children of 611 years of age, five out of ten samples found that parental modelling was positively associated with vegetable consumption, while unrelated in five samples (Pearson et al., 2009). It is yet important to notice that previous research often has assessed modelling by assessing parental diet; though parental diet and parental modelling are two distinct concepts (Vaughn et al., 2016).

\section{Negative parental attitudes}

The factor "negative parental attitudes" included four items measuring negative attitudes towards vegetable intake in parents. The included items were modified items taken from the factor "Respondent Doesn't Like Vegetables" in a study assessing parental vegetable feeding practices among American 3-5 year-olds (Baranowski et al., 2013). The reported correlation between that factor and "Child doesn't like vegetables" was 0.39 (Baranowski et al., 2013). In the present study, the mean value for the factor was low (1.31), indicating that most parents disagreed with the items included in this factor. Increasing values for this factor, implying more negative attitudes towards vegetable 
consumption, was significantly associated with less variety in vegetable intake and lower amount of vegetables consumed. This finding might be a reflection of both low availability and accessibility of vegetables in the home as this factor included the items "It is not important for me that my child eats vegetables", "It is not important for my partner that my child eats vegetables", "I don't like vegetables" and "My partner doesn't like vegetables". Further, it might also be that this factor reflects what Vaughn et al. labels "unstructured practices" due to a lack of parental involvement in vegetable consumption (Vaughn et al., 2016).

\section{Family demand}

In previous research, pressure to eat is often negatively associated with vegetable intake (Johnson, 2016). However, recent research has been more directed to make a distinction between practices where parents insist or demands the child to eat more food in general, and those that use pressure to eat more healthy food items like vegetables (Vaughn et al., 2016). In the review by Pearson et al.(Pearson et al., 2009), a positive association between family rules (demand/allow) and vegetable consumption was found in three out of three samples while pressure to eat was positively associated with vegetable intake in one out of three samples, and unrelated in the other two samples. Zeinstra and co-workers reported in their study that "pressure" was positively related to vegetable intake among the 4-12 yearolds (Zeinstra et al., 2010). Items included was: "When you give your child vegetables, does he/she have to eat the whole portion?", "Are you strict with your child concerning eating of vegetables?" and "Do you make your child eat vegetables when he/she doesn't want to?". In the present study, the factor "family demand" included items comparable to those in the study by Zeinstra et al. (Zeinstra et al., 2010) (e.g. "I insist that my child should sit at the table until all vegetables on his/her plate are eaten" and "My child should always eat all vegetables on his/her plate"). However, this factor was only positively associated with variety in vegetable intake among children of highly educated mothers, while no such association was seen among children of low educated mothers. It is not clear whether mothers with low education have less rules or less expectations with regard to vegetable intake compared to higher educated mothers; this interaction needs to be examined further.

We acknowledge that there are a large number of instruments developed to assess parental feeding practices in general and that the quality of the instruments is not always acceptable (Vaughn et al., 2016). We therefore have attempted to relate the development of this instrument to the suggested steps by Vaughn et al. (Vaughn et al., 2013): a clear conceptualization of what the instrument is intended to measure (step 1), a systematic process for developing (step 2) and refining the item pool (step 3), assessment of the instrument's reliability (step 4), validity (step 5), and responsiveness (step 6) (Vaughn et al., 2013). Ideally, we would have used an existing instrument to measure the sociocultural home environment of Norwegian preschool children at the time when the BRA-study was developed. However, as few instruments have focused solely on vegetable consumption among preschool 
children, we did not find an instrument that suited our purpose. We decided to include and modify items from statements and questions used in previous Norwegian and international studies among children (Baranowski et al., 2013; Bjelland et al., 2011; Haszard et al., 2013; Musher-Eizenman \& Holub, 2007; O'Connor et al., 2010; Zeinstra et al., 2010). Owing to time limits, we were not able to do a refinement of the item pool by doing factor analyses of the instrument, nor assessment of its psychometric properties prior to using it. However, to assess face validity and clarity of items, the instrument was tested in a pilot study and then revised. As described in this paper, PCA has been conducted on the item pool, and internal reliability of the factors resulting from the PCA has been assessed. Further, the construct validity by assessing the relationship between factors and three measures of vegetable consumption have been explored. Finally, we are planning to test the responsiveness of the instrument as is has been administrated to the participants at both baseline and at follow-up I.

\section{Strengths and limitations}

We observed differences in strength of associations between factors and how vegetable consumption was characterized; this supports the view that variety, frequency and amount of vegetables are different aspects of the behavior of vegetable intake and that these aspects might be associated with different factors. For that reason, this study presents a broad picture of potential relationships of associations between sociocultural home environmental factors and children's vegetable consumption. As most children in Norway attend kindergarten for many hours every week, parental ability to recall their child's diet when in child-care may be a limiting factor (Andersen et al., 2011; Baranowski et al., 1991). This was also supported by the parents in the present study, as more than 40 responders of the $24 \mathrm{~h}$ recall (step 3) gave feedback regarding difficulties in reporting intake when child was in kindergarten (data not shown). Therefore, to collect a more precise picture of vegetable intake, parental reports were combined with observations by the research staff (Foster \& Adamson, 2014). Interpretation of findings should also take some limitations into account. First, the data are crosssectional, and can thus only demonstrate associations. Further, there are many factors that we didn't include in our model that may affect children's intake of vegetables. Example of such factors are factors related to the child (like emotional eating, enjoyment of food, food neophobia and picky/fussy eating) and factors related to the parents (like parental intake of vegetables and parental food neophobia). The ideal model would have included all such factors. Additionally, the participation rate among parents in the present study is lower than participation rates in national dietary surveys among Norwegian preschool children (Kristiansen et al., 2009; Norwegian Directorate of Health, 2002;

Øverby et al., 2009); this might have led to a biased sample of those most interested in vegetables. The level of parental education in our sample of participants was higher compared to the national educational level in Norway and this might also have influenced the findings. In Norway, 39\% of men and 55\% of women aged 35-39 years had a high educational level in 2015 (Statistics Norway), 
compared to 54\% and $71 \%$, respectively, in the present study. Finally, in the present study, daily intake of vegetables was approximately 120 grams, while among Norwegian 2- and 4-year-olds intake has been measured to roughly 50-70 grams a day (Kristiansen et al., 2009; Norwegian Institute of Public Health, 2016a). There are many reasons for such discrepancies, like methodological differences between the surveys, but equally important is the detailed focus on vegetable intake in the present study that in itself can result in an overestimation of intake, while the focus in the national surveys was mapping the total diet.

\section{Conclusion}

Examining item pools to assess the sociocultural home environment of Norwegian preschool children resulted in seven distinct factors with for most satisfactory psychometric properties. Linear regression of the associations between vegetable intake and the factors showed, as expected, generally positive associations with "child involvement", "practical role model" and "family demand", and negative associations with "reward" and "negative parental attitudes". Unexpectedly, "reactive encouragement" was negatively associated with vegetable consumption. In addition, factors performed differently across educational groups and according to how vegetable consumption was assessed pointing to a need for further comparable studies. However, targeting the sociocultural home environment of preschool children in future interventions seems essential as there are important modifiable factors that both promote and hinder vegetable consumption in this environment.

\section{Acknowledgements}

This work was supported by the Research Council of Norway (project number 228452) with supplementary funds from the Throne Holst Nutrition Research Foundation, University of Oslo. The authors declare no conflict of interest. ALK conducted the statistical analyses and wrote the draft of the manuscript. ALK, MB, NL and LFA participated in designing the BRA-study. All authors participated in project planning and data collection. All authors have critically revised the manuscript, and read and approved the final version of the manuscript.

The authors are grateful to all children, their parents and the kindergarten staff who participated in the BRA-study.

\section{Figure legend}

Figure 1 A flow chart of recruitment and data collection of invited and participating 3-5 year olds children in the BRA-study at total and according to methods used in relation to the home environment at baseline. 


\section{References}

552

553

554

555

556

557

558

559

560

561

562

563

564

565

566

567

568

569

570

571

572

573

574

575

576

577

578

579

580

581

582

583

584

585

586

587

588

589

590

591

592

593

594

Andersen, L. F., Lioret, S., Brants, H., Kaic-Rak, A., de Boer, E. J., Amiano, P., \& Trolle, E. (2011). Recommendations for a trans-European dietary assessment method in children between 4 and 14 years. Eur J Clin Nutr, 65 Suppl 1, S58-64. doi:10.1038/ejcn.2011.88

Baranowski, T., Beltran, A., Chen, T. A., Thompson, D., O'Connor, T., Hughes, S., . . Baranowski, J. (2013). Psychometric assessment of scales for a Model of Goal Directed Vegetable Parenting Practices (MGDVPP). Int J Behav Nutr Phys Act, 10, 110. doi:10.1186/1479-5868-10-110

Baranowski, T., Sprague, D., Baranowski, J. H., \& Harrison, J. A. (1991). Accuracy of maternal dietary recall for preschool children. J Am Diet Assoc, 91(6), 669-674.

Bjelland, M., Brantsaeter, A. L., Haugen, M., Meltzer, H. M., Nystad, W., \& Andersen, L. F. (2013). Changes and tracking of fruit, vegetables and sugar-sweetened beverages intake from 18 months to 7 years in the Norwegian Mother and Child Cohort Study. BMC Public Health, 13, 793. doi:10.1186/1471-2458-13-793

Bjelland, M., Lien, N., Grydeland, M., Bergh, I. H., Anderssen, S. A., Ommundsen, Y., . . Andersen, L. F. (2011). Intakes and perceived home availability of sugar-sweetened beverages, fruit and vegetables as reported by mothers, fathers and adolescents in the HEIA (HEalth In Adolescents) study. Public Health Nutr, 14(12), 2156-2165. doi:10.1017/s1368980011000917

Blanchette, L., \& Brug, J. (2005). Determinants of fruit and vegetable consumption among 6-12-yearold children and effective interventions to increase consumption. J Hum Nutr Diet, 18(6), 431-443. doi:10.1111/j.1365-277X.2005.00648.x

Blissett, J. (2011). Relationships between parenting style, feeding style and feeding practices and fruit and vegetable consumption in early childhood. Appetite, 57(3), 826-831. doi:10.1016/j.appet.2011.05.318

Cook, L. T., O'Reilly, G. A., DeRosa, C. J., Rohrbach, L. A., \& Spruijt-Metz, D. (2015). Association between home availability and vegetable consumption in youth: a review. Public Health Nutr, 18(4), 640-648. doi:10.1017/s1368980014000664

Craigie, A. M., Lake, A. A., Kelly, S. A., Adamson, A. J., \& Mathers, J. C. (2011). Tracking of obesityrelated behaviours from childhood to adulthood: A systematic review. Maturitas, 70(3), 266284. doi:10.1016/j.maturitas.2011.08.005

de Lauzon-Guillain, B., Oliveira, A., Charles, M. A., Grammatikaki, E., Jones, L., Rigal, N., . . MonneryPatris, S. (2012). A review of methods to assess parental feeding practices and preschool children's eating behavior: the need for further development of tools. J Acad Nutr Diet, 112(10), 1578-1602, 1602.e1571-1578. doi:10.1016/j.jand.2012.06.356

DeCosta, P., Moller, P., Frost, M. B., \& Olsen, A. (2017). Changing children's eating behaviour - A review of experimental research. Appetite, 113, 327-357. doi:10.1016/j.appet.2017.03.004

Field, A. (2009). Discovering Statistics using IBM SPSS Statistics (Vol. 3rd edition). London: SAGE Publications Ltd.

Foster, E., \& Adamson, A. (2014). Challenges involved in measuring intake in early life: focus on methods. Proc Nutr Soc, 73(2), 201-209. doi:10.1017/s0029665114000020

Gevers, D. W., Kremers, S. P., de Vries, N. K., \& van Assema, P. (2014). Clarifying concepts of food parenting practices. A Delphi study with an application to snacking behavior. Appetite, 79, 51-57. doi:10.1016/j.appet.2014.04.002

Glasson, C., Chapman, K., \& James, E. (2011). Fruit and vegetables should be targeted separately in health promotion programmes: differences in consumption levels, barriers, knowledge and 
stages of readiness for change. Public Health Nutr, 14(4), 694-701. doi:10.1017/s1368980010001643

Haszard, J. J., Williams, S. M., Dawson, A. M., Skidmore, P. M., \& Taylor, R. W. (2013). Factor analysis of the Comprehensive Feeding Practices Questionnaire in a large sample of children. Appetite, 62, 110-118. doi:10.1016/j.appet.2012.11.017

Heck, R., Thomas, S., \& Tabata, L. (2010). Multilevel and longitudinal modeling with IBM SPSS. New York: Routledge Taylor \& Francis Group.

Hu, D., Huang, J., Wang, Y., Zhang, D., \& Qu, Y. (2014). Fruits and vegetables consumption and risk of stroke: a meta-analysis of prospective cohort studies. Stroke, 45(6), 1613-1619. doi:10.1161/strokeaha.114.004836

Johnson, S. L. (2016). Developmental and Environmental Influences on Young Children's Vegetable Preferences and Consumption. Adv Nutr, 7(1), 220s-231s. doi:10.3945/an.115.008706

Kline P. (1994). An easy guide to factor analysis. London: Routledge.

Kristiansen, A. L., Bjelland, M., Himberg-Sundet, A., Lien, N., \& Andersen, L. F. (2017). Associations between physical home environmental factors and vegetable consumption among Norwegian 3-5-year-olds: the BRA-study. Public Health Nutr, 20(7), 1173-1183. doi:10.1017/s1368980016003396

Kristiansen, A. L., Lande, B., \& Andersen, L. F. (2009). Småbarnskost 2007 - Dietary habits among 2year-old children in Norway (in Norwegian) (IS-1731). Retrieved from Oslo: https://helsedirektoratet.no/Lists/Publikasjoner/Attachments/702/Smabarnskost-2007landsomfattende-kostholdsundersokelse-blant-2-ar-gamle-barn-IS-1731.pdf

Krolner, R., Rasmussen, M., Brug, J., Klepp, K. I., Wind, M., \& Due, P. (2011). Determinants of fruit and vegetable consumption among children and adolescents: a review of the literature. Part II: qualitative studies. Int J Behav Nutr Phys Act, 8, 112. doi:10.1186/1479-5868-8-112

Li, M., Fan, Y., Zhang, X., Hou, W., \& Tang, Z. (2014). Fruit and vegetable intake and risk of type 2 diabetes mellitus: meta-analysis of prospective cohort studies. BMJ Open, 4(11), e005497. doi:10.1136/bmjopen-2014-005497

Lien, N., Lytle, L. A., \& Klepp, K. I. (2001). Stability in consumption of fruit, vegetables, and sugary foods in a cohort from age 14 to age 21. Prev Med, 33(3), 217-226. doi:10.1006/pmed.2001.0874

McGowan, L., Croker, H., Wardle, J., \& Cooke, L. J. (2012). Environmental and individual determinants of core and non-core food and drink intake in preschool-aged children in the United Kingdom. Eur J Clin Nutr, 66(3), 322-328. doi:10.1038/ejcn.2011.224

Micha, R., Khatibzadeh, S., Shi, P., Andrews, K. G., Engell, R. E., \& Mozaffarian, D. (2015). Global, regional and national consumption of major food groups in 1990 and 2010: a systematic analysis including 266 country-specific nutrition surveys worldwide. BMJ Open, 5(9), e008705. doi:10.1136/bmjopen-2015-008705

Musher-Eizenman, D., \& Holub, S. (2007). Comprehensive Feeding Practices Questionnaire: validation of a new measure of parental feeding practices. J Pediatr Psychol, 32(8), 960-972. doi:10.1093/jpepsy/jsm037

Norwegian Directorate of Health. (2002). Ungkost-Dietary habits among 4-year-olds (in Norwegian) (IS-1067). Retrieved from Oslo: https://helsedirektoratet.no/Lists/Publikasjoner/Attachments/324/Ungkost-2000landsomfattende-kostholdsundersokelse-blant-4-aringer-IS-1067.pdf

Norwegian Directorate of Health. (2012). Norkost 3 - Dietary habits among adults in Norway in 201011 (in Norwegian) (IS-2000). Retrieved from Oslo: https://helsedirektoratet.no/Lists/Publikasjoner/Attachments/301/Norkost-3-enlandsomfattende-kostholdsundersokelse-blant-menn-og-kvinner-i-norge-i-alderen-18-70-ar2010-11-IS-2000.pdf

Norwegian Directorate of Heath. (2012). Meals, physical activity and environment health care in kindergartens (in Norwegian) (IS-0345). Retrieved from Oslo: https://helsedirektoratet.no/Lists/Publikasjoner/Attachments/299/Maltider-fysisk-aktivitet- 
og-miljorettet-helsevern-i-barnehagen-en-undersokelse-blant-styrere-og-pedagogiskeledere-IS-0345.pdf

Norwegian Institute of Public Health. (2016a). Ungkost 3 - Dietary intake among 4 year olds in 2016 (in Norwegian). Retrieved from Oslo: https://www.fhi.no/globalassets/dokumenterfiler/rapporter/rapport-ungkost-3landsomfattende-kostholdsundersokelse-blant-4-aringer-i-norge-2016.pdf

Norwegian Institute of Public Health. (2016b). Ungkost 3 - Dietary intake among 9 and 13-year olds in 2015 (in Norwegian). Retrieved from Oslo: https://www.fhi.no/globalassets/dokumenterfiler/rapporter/ungkost-rapport-24.06.16.pdf Nunnally JC, B. I. (1994). Psychometric Theory (Vol. 2nd edition). New York: McGraw-Hill. O'Connor, T. M., Hughes, S. O., Watson, K. B., Baranowski, T., Nicklas, T. A., Fisher, J. O., . . . Shewchuk, R. M. (2010). Parenting practices are associated with fruit and vegetable consumption in pre-school children. Public Health Nutr, 13(1), 91-101. doi:10.1017/s1368980009005916

O'Connor, T. M., Pham, T., Watts, A. W., Tu, A. W., Hughes, S. O., Beauchamp, M. R., ... Masse, L. C. (2016). Development of an item bank for food parenting practices based on published instruments and reports from Canadian and US parents. Appetite, 103, 386-395. doi:10.1016/j.appet.2016.04.033

Patro-Golab, B., Zalewski, B. M., Kolodziej, M., Kouwenhoven, S., Poston, L., Godfrey, K. M., ... Szajewska, H. (2016). Nutritional interventions or exposures in infants and children aged up to 3 years and their effects on subsequent risk of overweight, obesity and body fat: a systematic review of systematic reviews. Obes Rev, 17(12), 1245-1257. doi:10.1111/obr.12476

Pearson, N., Biddle, S. J., \& Gorely, T. (2009). Family correlates of fruit and vegetable consumption in children and adolescents: a systematic review. Public Health Nutr, 12(2), 267-283. doi:10.1017/s1368980008002589

Rasmussen, M., Krolner, R., Klepp, K. I., Lytle, L., Brug, J., Bere, E., \& Due, P. (2006). Determinants of fruit and vegetable consumption among children and adolescents: a review of the literature. Part I: Quantitative studies. Int J Behav Nutr Phys Act, 3, 22. doi:10.1186/1479-5868-3-22

Rosenkranz, R. R., \& Dzewaltowski, D. A. (2008). Model of the home food environment pertaining to childhood obesity. Nutr Rev, 66(3), 123-140. doi:10.1111/j.1753-4887.2008.00017.x

Statistics Norway. Population's level of education 2015. Retrieved from https://ssb.no/en/utdanning/statistikker/utniv/aar/2016-0620?fane=tabell\&sort=nummer \&tabell $=270244$

Tandon, P. S., Tovar, A., Jayasuriya, A. T., Welker, E., Schober, D. J., Copeland, K., . . W Ward, D. S. (2016). The relationship between physical activity and diet and young children's cognitive development: A systematic review. Prev Med Rep, 3, 379-390. doi:10.1016/j.pmedr.2016.04.003

Tavakol, M., \& Dennick, R. (2011). Making sense of Cronbach's alpha. International Journal of Medical Education, 2, 53-55. doi:10.5116/ijme.4dfb.8dfd

Totland, T. H., Gebremariam, M. K., Lien, N., Bjelland, M., Grydeland, M., Bergh, I. H., . . Andersen, L. F. (2013). Does tracking of dietary behaviours differ by parental education in children during the transition into adolescence? Public Health Nutr, 16(4), 673-682. doi:10.1017/s1368980012003060

van der Horst, K., Oenema, A., Ferreira, I., Wendel-Vos, W., Giskes, K., van Lenthe, F., \& Brug, J. (2007). A systematic review of environmental correlates of obesity-related dietary behaviors in youth. Health Educ Res, 22(2), 203-226. doi:10.1093/her/cyl069

Vaughn, A. E., Tabak, R. G., Bryant, M. J., \& Ward, D. S. (2013). Measuring parent food practices: a systematic review of existing measures and examination of instruments. Int J Behav Nutr Phys Act, 10, 61. doi:10.1186/1479-5868-10-61 
Vaughn, A. E., Ward, D. S., Fisher, J. O., Faith, M. S., Hughes, S. O., Kremers, S. P., . . Power, T. G. (2016). Fundamental constructs in food parenting practices: a content map to guide future research. Nutr Rev, 74(2), 98-117. doi:10.1093/nutrit/nuv061

Vereecken, C. A., Keukelier, E., \& Maes, L. (2004). Influence of mother's educational level on food parenting practices and food habits of young children. Appetite, 43(1), 93-103. doi:10.1016/j.appet.2004.04.002

Wang, X., Ouyang, Y., Liu, J., Zhu, M., Zhao, G., Bao, W., \& Hu, F. B. (2014). Fruit and vegetable consumption and mortality from all causes, cardiovascular disease, and cancer: systematic review and dose-response meta-analysis of prospective cohort studies. Bmj, 349, g4490. doi:10.1136/bmj.g4490

Zalewski, B. M., Patro, B., Veldhorst, M., Kouwenhoven, S., Crespo Escobar, P., Calvo Lerma, J., .. . Szajewska, H. (2017). Nutrition of infants and young children (one to three years) and its effect on later health: A systematic review of current recommendations (EarlyNutrition project). Crit Rev Food Sci Nutr, 57(3), 489-500. doi:10.1080/10408398.2014.888701

Zeinstra, G. G., Koelen, M. A., Kok, F. J., van der Laan, N., \& de Graaf, C. (2010). Parental child-feeding strategies in relation to Dutch children's fruit and vegetable intake. Public Health Nutr, 13(6), 787-796. doi:10.1017/s1368980009991534

$\emptyset$ verby, N. C., Kristiansen, A. L., Andersen, L. F., \& Lande, B. (2009). Spedkost 12 måneder Norwegian national dietary survey among infants at 12 months (in Norwegian) (IS-1635). Retrieved from Oslo: https://helsedirektoratet.no/Lists/Publikasjoner/Attachments/704/Spedkost-12-manederlandsomfattende-kostholdundersokelse-2007-IS-1635.pdf 